stress tended to be lower at the radius on follow-up however these parameters were not significantly different at the tibia (table 1).

Abstract AB0843 - Table 1

\begin{tabular}{lcccccc}
\hline & \multicolumn{2}{c}{ RADIUS } & \multicolumn{3}{c}{ TIBIA } \\
\hline & Baseline & Follow-up & $\mathbf{p}$ & Baseline & Follow-up & $\mathbf{p}$ \\
\hline Total volumetric BMD & 318.93 & 317.37 & 0.49 & 301.89 & 302.06 & 0.70 \\
$\left(\mathrm{mg} / \mathrm{cm}^{3}\right.$ ) & \pm 311.80 & \pm 378.61 & & \pm 48.99 & \pm 50.71 & \\
Cortical volumetric & 857.22 & 851.48 & 0.08 & 869.69 & 866.62 & 0.11 \\
BMD $\left(\mathrm{mg} / \mathrm{cm}^{3}\right.$ ) & \pm 51.43 & \pm 52.96 & & \pm 38.21 & \pm 39.91 & \\
Trabecular volumetric & 158.33 & 156.81 & 0.21 & 155.200 & 154.26 & 0.35 \\
BMD $\left(\mathrm{mg} / \mathrm{cm}^{3}\right.$ ) & \pm 42.34 & \pm 41.88 & & \pm 44.34 & \pm 45.25 & \\
BV/TV $(\%)$ & 0.132 & 0.131 & 0.19 & 0.129 & $0.129 \pm 0.04$ & 0.37 \\
& \pm 0.035 & \pm 0.035 & & \pm 0.037 & & \\
Trabecular number & 1.985 & 2.017 & 0.32 & 1.793 & $1.809 \pm 0.37$ & 0.56 \\
(per mm ${ }^{3}$ ) & \pm 0.302 & \pm 0.319 & & \pm 0.36 & & \\
Trabecular thickness & 0.067 & 0.065 & 0.12 & 0.072 & $0.071 \pm 0.01$ & 0.17 \\
(mm) & \pm 0.013 & \pm 0.013 & & \pm 0.01 & & \\
Trabecular separation & 0.435 & 0.429 & 0.46 & 0.483 & $0.478+0.13$ & 0.06 \\
(mm) & \pm 0.104 & \pm 0.106 & & \pm 0.13 & & \\
Cortical thickness & 0.765 & 0.760 & 0.80 & 0.751 & 0.745 & 0.78 \\
(mm) & $(0.72-$ & $(0.71-0.82)$ & & $(0.58-$ & $(0.55-0.83)$ & \\
& $0.85)$ & & & $0.84)$ & & \\
Cortical porosity (\%) & 0.019 & 0.017 & 0.81 & 0.049 & 0.048 & 0.80 \\
& $(0.71-$ & $(0.016-$ & & $(0.02-$ & $(0.017-$ & \\
& $0.82)$ & $0.024)$ & & $0.06)$ & $0.065)$ & \\
Stiffness (N/mm) & $1.37 \pm 0.42$ & $1.33 \pm 0.34$ & 0.03 & $1.57 \pm 0.31$ & $1.58 \pm 0.31$ & 0.72 \\
Stress (MPa) & 27.23 & $26.30 \pm 9.83$ & 0.03 & $32.78 \pm 7.8$ & $32.70 \pm 7.71$ & 0.71 \\
& \pm 10.52 & & & & & \\
\hline & & & & & &
\end{tabular}

Conclusions: This is the first study to document the changes in bone strength in AS patients with the use of TNF inhibitors. Treatment with TNF inhibitors might maintain bone microarchitecture at cortical and trabecular sites in patients with AS.

Disclosure of Interest: N. Nigil Haroon Consultant for: AMGEN Canada, E. Szabo: None declared, A. CHEUNG Consultant for: AMGEN, ELI LILLY, R. Inman Grant/research support from: AMGEN, Consultant for: AMGE, ABBVIE, NOVARTIS, JANNSEN, MERCK

DOI: 10.1136/annrheumdis-2018-eular.1023

\section{AB0844 EFECTIVENESS AND RETENTION RATE OF CERTOLIZUMAB PEGOL IN SPONDYLOARTHRITIS. REAL LIFE DATA}

R. Expósito-Molinero $^{1}$, R. Garcia-Portales ${ }^{2}$, J.R. Lamua-Riazuelo ${ }^{3}$, A. Urruticoechea-Arana ${ }^{4}$, P. Navarro-Alonso ${ }^{5}$, J.S. Rey-Rey ${ }^{6}$, M. FernandezPrada $^{7}$, C.M. Gonzalez Fernandez ${ }^{8}$, on behalf of RENACER Study Group. ${ }^{1}$ Rheumatology, Hospital Comarcal de Laredo, Laredo; ${ }^{2}$ Rheumatology, Hospital Virgen de la Victoria, Malaga; ${ }^{3}$ Rheumatology, Hospital del Henares, Alcala de Henares; ${ }^{4}$ Rheumatology, Hospital Can Misses, Ibiza; ${ }^{5}$ Rheumatology, Hospital de Fuenlabrada, Fuenlabrada; ${ }^{6}$ Rheumatology, Hospital Virgen de la Salud, Toledo; ${ }^{7}$ Rheumatology, Hospital Universitario de Guadalajara, Guadalajara;

${ }^{8}$ Rheumatology, Hospital General Universitario Gregorio Marañón, Madrid, Spain

Background: Certolizumab pegol (CZP) is available for patients with axial spondyloarthritis (axSpA), including ankylosing spondylitis (AS) and non-radiographic axial spondyloarthritis (nr-axSpA). The efficacy and the safety of CZP are well established from clinical trials. However, evidence of its effectiveness in regular clinical practice is limited.

Objectives: To evaluate the effectiveness and safety of CZP in a real word setting in axSpA patients.

Methods: Multicentric cohort of SpA patients treated with CZP according to routine clinical practice. The study was approved by the local Ethics Committee. Maximum follow-up was 12 months. Clinical response was evaluated through BASDAI, ASDAS, BASFI and MASES scores. Safety variables: discontinuation rate.

Results: 336 patients with axSpA were included: $56.5 \%$ male, mean age 45.8 $( \pm 12.1)$ years, median disease time $4.3(0,49.5)$ years, $68.5 \%$ of patients were HLAB27 positive, and never smokers $64.7 \%$. Prior bDMARD received $(27.2 \%$ none; $37.9 \% 1,35 \%>2$ ). At baseline $36.8 \%$ had concomitant DMARDs and $82.8 \%$ NSAIDs. $31.8 \%$ of patients had peripheral arthritis and $42.7 \%$ entesitis at baseline. CZP retention time 10.3 months. Statistically significant differences in BASDAI, BASFI, ASDAS y MASES were observed at the last visit comparing to baseline (table 1). In the last observation, $41.0 \%$ of the patients achieved BASDAI50, 34\% were in ASDAS remission (ASDAS <1.3) and $49 \%$ presented a minimal clinical improvement (ASDAS at least 1.1). $46.3 \%$ of patients had resolution of the enthesitis (MASES=0). According to Kaplan-Meier analysis, the drug survival of CZP was $83.3 \%$, and no differences were observed in retention rates when CZP were used as first option (83.3\%) or after failure to other biologicals (79.1\%) (figure 1). 56/336 (16.7\%) withdrawn CZP treatment: $34 / 336(10.1 \%)$ due to lack of effectiveness, $16 / 336$ (4.8\%) due to adverse event and 6/336 (1.8\%) for other reason. Serious adverse event was found in 23/336 (6.8\%) patients.

Abstract AB0844 - Table 1. Evolution of clinical variables of activity

\begin{tabular}{lcc}
\hline & Baseline & Last visit \\
\hline BASDAI evolution & $6,2 \pm 1.6(n=263)$ & $3,9 \pm 2.2(n=260)^{*}$ \\
BASFI evolution & $5,6 \pm 2.1(n=225)$ & $3,7 \pm 2.3(n=241)^{\star}$ \\
ASDAS evolution & $3.7 \pm 2.7(n=322)$ & $2,4 \pm 2.2(n=321)^{\star}$ \\
MASES score & $3,9 \pm 2.7(n=78)$ & $1,2 \pm 1.8(n=51)^{*}$ \\
\hline
\end{tabular}

${ }^{*} \mathrm{p}<0,001$, Wilcoxon's test

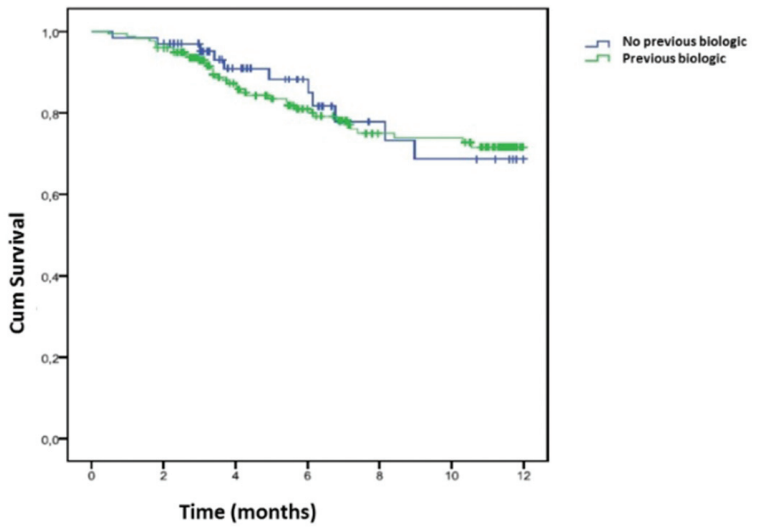

Abstract AB0844 - Figure 1. CZP Retention rate in axSpA patients without and with previous biological experience.

Conclusions: Real life experience from this nationwide rheumatology study, demonstrated the effectiveness and safety of CZP in patients with axSpA, with a significant reduction of BASDAI, BASFI, ASDAS and MASES scores. No differences were observed in the retention rate regardless previous biological treatment. Disclosure of Interest: R. Expósito-Molinero: None declared, R. Garcia-Portales Consultant for: Celgene, Speakers bureau: UCB, Pfizer, Roche, J. R. Lamua-Riazuelo: None declared, A. Urruticoechea-Arana: None declared, P. Navarro-Alonso: None declared, J. S. Rey-Rey Speakers bureau: UCB, Abbvie, Pfizer, BMS, Roche, Celgene, M. Fernandez-Prada: None declared, C. Gonzalez Fernandez Consultant for: MSD, Janssen, Novartis, Celgene, Speakers bureau: Abbie, Janssen, MSD, Novartis, Roche, UCB, BMS DOI: 10.1136/annrheumdis-2018-eular.5552

\section{AB0845 THE EFFECT OF BIOLOGIC DISEASE-MODIFYING ANTIRHEUMATIC DRUGS PATIENT REPORTED OUTCOMES IN PATIENTS WITH AXIAL SPONDYLOARTHRITIS; A SYSTEMATIC LITERATURE REVIEW AND A CALL FOR ACTION}

S. Rodrigues-Manica ${ }^{1,2}$, J. Leite Silva ${ }^{3}$, A.R. Machado ${ }^{4}$, C. Coelho ${ }^{5}$, J. Duarte ${ }^{6}$, E. Vieira-Sousa ${ }^{4}$, J. Tavares-Costa ${ }^{3}$, F.M. Pimentel-Santos ${ }^{1,2} .{ }^{1}$ CEDOC; ${ }^{2}$ Egas Moniz, Centro Hospitalar de Lisboa Ocidental, Lisbon; ${ }^{3}$ Unidade Local de Saúde do Alto Minho, Ponte de Lima; ${ }^{4}$ Centro Hospitalar de Lisboa Norte, EPE, Hospital de Santa Maria, Lisbon Academic Medical Centre; ${ }^{5}$ Genetics Laboratory, Institute of Environmental Health, Lisbon School of Medicine, University of Lisbon; ${ }^{6}$ Medical Department, Novartis Pharma, Pharmaceutical products, Lisbon, Portugal

Background: Patient reported outcomes (PROs) have gained relevance in the evaluation of several diseases such as axial spondyloarthritis (axSpA). They allow the clinician to have a quantitative measurement of several aspects of the dis ease, according to the patient perspective.

Objectives: In this review we intended to evaluate the efficacy of different biologic disease-modifying anti-rheumatic drugs (bDMARD) in achieving the minimum clinically important difference (MCID) in several PROS's. Data from randomised controlled trials (RCT) conducted in radiographic axSpA ( $r$-axSpA) and non-radiographic axSpA (nr-AxSpA) patients were included.

Methods: A systematic literature review (SLR) was performed using the MED LINE database (August 17 2017) with the filters "published in the last 10 years" and "humans". Abstracts from the EULAR 2017 were also considered. The PICO (P 
population; I, intervention; C, comparison; O, outcome) concept was used to perform the analysis according to: Patients: adults (>18 years old) with r-axSpA or nraxSpA; Intervention: any bDMARD regardless of formulation or duration; Comparison: placebo and/or any different drug; Outcomes: The Bath Ankylosing Spondylitis Functional Index (BASFI), the Ankylosing Spondylitis Quality of Life (ASQoL), the EuroQol-5D (EQ-5D), the Short Form 36 Health Survey physical component summary (SF36-PCS), the Short Form 36 Health Survey mental component summary (SF36-MCS), and the Functional Assessment of Chronic Illness Therapy Facit (FACIT-F). For each outcome we assessed whether the treatment group was superior, equal or inferior to the placebo (PBO) group regarding the achievement of the MCID of the assessed PRO over time.

Results: After screening 557 references (after de-duplication), 16 RCTs were included, studying interleukin 17 inhibitors (IL17i) and tumour necrosis factor inhibitors (TNFi). In r-axSpA, the treatment group (for both TNFi and IL17i) reached the MCID for all the assessed PROs, except for a single study in which both the treatment and PBO groups reached the MCID for the SF36-PCS. For nraxSpA the results were more heterogeneous (table 1).

Abstract AB0845 - Table 1

\begin{tabular}{|c|c|c|c|}
\hline Phenotype & $\begin{array}{l}\mathrm{PRO} \text { and } \mathrm{MCID} \\
\text { cut-off for } \\
\text { improvement }\end{array}$ & $\begin{array}{c}\text { Difference } \\
\text { between } \mathrm{MCID} \\
\text { from baseline to } \\
\text { RCT end in favour } \\
\text { of treatment arm } \\
\text { (against PBO) }\end{array}$ & Drug (reference) \\
\hline \multirow[t]{7}{*}{ r-AxSpA } & $\begin{array}{l}\text { BASFI (0-10) } \\
(\geq 7 \mathrm{~mm})\end{array}$ & YES & $\begin{array}{l}\text { ADA (Maksy 2008); SEC (Deodhar 2017); } \\
\text { ADA (van der Heijde 2009) }\end{array}$ \\
\hline & $\begin{array}{l}\text { ASQoL (0-18) } \\
(\geq 1.8)\end{array}$ & YES & $\begin{array}{l}\text { SEC (Deodhar 2017); GOL (Deodhar } \\
\text { 2017) }\end{array}$ \\
\hline & $E Q-5 D(\geq 10.0)$ & YES & $\begin{array}{l}\text { SEC (Deodhar 2017;Marzo-Ortega } \\
\text { 2017); GOL (Reveille 2017) }\end{array}$ \\
\hline & $\begin{array}{l}\text { SF36-PCS } \\
(\geq 2.5)\end{array}$ & YES & $\begin{array}{l}\text { SEC (Deodhar 2017; Marzo-Ortega } \\
\text { 2017) }\end{array}$ \\
\hline & $\begin{array}{l}\text { SF36-PCS } \\
(\geq 2.5)\end{array}$ & YESH & GOL (van Heijde 2014; Reveille 2017) \\
\hline & $\begin{array}{l}\text { SF36-MCS } \\
(\geq 2.5)\end{array}$ & YES & $\begin{array}{l}\text { SEC (Deodhar 2017);GOL (van der Heijde } \\
\text { 2004; Reveille 2017) }\end{array}$ \\
\hline & FACIT-F (24) & YES & SEC (Kvien 2017; Kvien 2017) \\
\hline \multirow[t]{9}{*}{ nr-axSpA } & $\begin{array}{l}\text { BASFI (0-10) } \\
(\geq 7 \mathrm{~mm})\end{array}$ & YES & ETN (Maksymowych 2016) \\
\hline & $\begin{array}{l}\text { BASFI (0-10) } \\
(\geq 7 \mathrm{~mm})\end{array}$ & YESH & ADA (Haibel 2008);IFX (Sieper 2014) \\
\hline & $\begin{array}{l}\text { ASQoL (0-18) } \\
(\geq 1.8)\end{array}$ & YES & CZP (Sieper 2015) \\
\hline & EQ-5D (210.0) & YESH & ADA (Haibel 2008);IIFX (Sieper 2014) \\
\hline & EQ-SD $(210.0)$ & NO & ETN (Dougados 2015) \\
\hline & $\begin{array}{l}\text { SF36-PCS } \\
(\geq 2.5)\end{array}$ & YES & ADA (Sieper 2013) \\
\hline & $\begin{array}{l}\text { SF36-PCS } \\
(\geq 2.5)\end{array}$ & YESH & ADA (Haibel 2008);ETN (Dougados 2015) \\
\hline & $\begin{array}{l}\text { SF36-MCS } \\
(\geq 2.5)\end{array}$ & YES & ADA (Haibel 2008) \\
\hline & $\begin{array}{l}\text { SF36-MCS } \\
(\geq 2.5)\end{array}$ & NO & ETN (Dougados 2015) \\
\hline
\end{tabular}

PRO: Patient reported outcome; RCT: Randomised control trial; PBO: Placebo; raxSpA: radiographic axial spondyloarthritis; nr-axSpA: non-radiographic axial spondyloarthritis; BASFI: The Bath Ankylosing Spondylitis Functional Index; ASQoL; Ankylosing Spondylitis Quality of Life Questionnaire; EQ-5FD; the EuroQol-5D; SF36-PCS: Short Form 36 Health Survey physical component summary; SF-36-MCS: the Short Form 36 Health Survey mental component summary; FACIT-F: the Functional Assessment of Chronic Illness Therapy - Facit; ADA: Adalimumab; SEK: Secukinumab; GOL: Golimumab; ETN: Etanercept; IFX: Infliximab; CZP: Certolizumab pegol; YES: There was an improvement on treatment but not on PBO groups; YES\# There was a MCID improvement in both treatment and $\mathrm{PBO}$ groups; NO: there was no improvement in neither treatment nor PBO group.

Conclusions: The assessment of PROs in RCT is scarce. The profile of PROs response seems to be different between r-axSpA and nr-axSpA patients; these differences must be further validated in future trials.

This study launches a call for action in PROs reporting standardisation.

\section{REFERENCES:}

[1] -Deodhar 2016; van der Heijde 2009; Sieper 2013; Haibel 2008; Maksymowych 2008; Dougados 2014; Maksymowych 2016; Dougados 2015; van der Heijde 2014; Deodhar Abstract THU0348. EULAR 2017; Reveille JD EULAR 2017; Park W 2016; Sieper 2014; Deodhar 2016; Marzo-Ortega 2017; Kvien TK Abstract THU0393 EULAR 2017; Sieper 2015.
Acknowledgements: Novartis Pharma for the logistic support.

Disclosure of Interest: S. Rodrigues-Manica: None declared, J. Leite Silva: None declared, A. R. Machado: None declared, C. Coelho Employee of: Novartis Pharma Portugal, J. Duarte Employee of: Novartis Pharma Portugal, E. VieiraSousa: None declared, J. Tavares-Costa: None declared, F. M. Pimentel-Santos: None declared

DOI: 10.1136/annrheumdis-2018-eular.5857

\section{AB0846 PERSONALISING CARE: USING INFLIXIMAB DRUG TROUGH AND ANTI-DRUG ANTIBODY LEVELS IMPROVES CLINICAL TREATMENT DECISIONS AND IS A COST EFFECTIVE STRATEGY IN SPONDYLOARTHRITIS}

S. Dubash ${ }^{1,2}$, D. Bryer ${ }^{2}$, J. Fitton ${ }^{1,2}$, A. Barr ${ }^{1,2}$, C. Vandevelde ${ }^{1,2}$, H. MarzoOrtega $^{1,2}$, J. Freeston ${ }^{1,2}$. ${ }^{1}$ Rheumatology, Leeds Institute of Rheumatic and Musculoskeletal Medicine, University of Leeds; ${ }^{2}$ Rheumatology, NIHR Leeds Biomedical Research Centre, Leeds Teaching Hospitals NHS Trust, Leeds, UK

Background: Personalised medicine tailors treatment to the individual's needs. The advent of biosimilars has led to therapy re-appraisals driven by healthcare commissioning bodies' demand forcost-effective interventions. Yet, biologic drug dosing is standardised and little is known about the rationale and efficacy of dose adjustment.

Objectives: As part of a service evaluation exercise, we measured serum drug trough levels (DLs) and anti-drug antibodies(ADAbs) in our cohort of patients with axial spondyloarthritis (axSpA) and Psoriatic arthritis (PsA) receiving bio-originator infliximab with the aims of a) informing our decision making upon switching to a biosimilar and $b$ ) assessing the impact of this approach to our clinical practice.

Methods: Eligible subjects identified, were counselled and consented by an experienced specialist nurse on DLs and ADAb testing and possible associated outcomes including change in drug class, dose, infusion time interval and switching from bio-originator infliximab to the biosimilar infliximab CT-P13. A treatment algorithm was developed to guide the treating physician. Clinical and outcome data were recorded as per routine practice including disease status, DLs and ADAb titre, and clinical outcome.

Results: We identified 53 subjects. Based upon disease activity, DL and ADAb level, bio-originator infliximab was discontinued in $3(6 \%)$ subjects, the infusion interval was extended in $8(15 \%)$, shortened in $3(6 \%)$, and the dose reduced in 3 $(6 \%)$ subjects. Four patients $(8 \%)$ changed to an alternative biologic due to persistent high disease activity on infliximab. ADAbs were absent in 20/28 (71\%) subjects on concomitant methotrexate (MTX). Very high titre ADAbs were identified in $8(15 \%)$ subjects with corresponding very low $(n=2)$ or undetectable $(n=6)$ DLs suggesting likely drug-neutralisation. The total estimated cost-savings from drug discontinuation and interval extension or dose reduction were £28,689 per annum in addition to the biosimilar switch saving of $£ 41,184$ per annum.

Abstract AB0846 - Table 1

\begin{tabular}{lcc}
\hline & $\begin{array}{c}\text { axSpA (n=32, } \\
\mathbf{6 0 \%}\end{array}$ & PsA (n=21, 40\%) \\
\hline M:F & $30: 1$ & $7: 14$ \\
Bio-originator infliximab duration (years), (median, & $11(8-15)$ & $9(6-14)$ \\
IQR) & $12(36 \%)$ & $17(81 \%)$ \\
Concomitant csDMARD, $\mathrm{n}(\%)$ & $12(100 \%, 15 \mathrm{mg} /$ & $16(94 \%, 10 \mathrm{mg} /$ \\
MTX, $\mathrm{n}(\%$, median dose) & week)) & week) \\
& $5(16 \%)$ & $5(24 \%)$ \\
Previous biologic (bDMARD) & $12(37 \%), 46.5$ & $8(38 \%), 86.5$ \\
Positive ADAbs (median, IQR) AU/mL & $(18-74)$ & $(29-212)$ \\
& $14(44 \%)$ & $10(48 \%)$ \\
Therapeutic range DL & $4(13 \%)$ & $4(27 \%)$ \\
High ADAb/very low or undetectable drug (likely & & \\
drug-neutralising) & $1(3 \%)$ & $2(10 \%)$ \\
$\begin{array}{l}\text { Drug discontinued (no alternative bDMARD } \\
\text { required) }\end{array}$ & $8(25 \%)$ & $3(14 \%)$ \\
$\begin{array}{l}\text { Dose reduced or interval extended } \\
\text { Alternative bDMARD (either TNFi or different mode }\end{array}$ & $1(3 \%)$ & $3(14 \%)$ \\
of action) & $14(44 \%)$ & $10(48 \%)$ \\
Switched to biosimilar & &
\end{tabular}

Conclusions: These data from a small cohort suggest that measuring ADAbs and DLs to characterise treatment response, tailor treatment regime and inform biosimilar switching is a clinically efficacious and cost-effective strategy in infliximab-treated SpA patients. We anticipate further significant savings with ou 